\title{
Hot-crack test for aluminium alloys welds using TIG process
}

\author{
A. Niel, ${ }^{\text {a }}$, F. Deschaux-beaume, C. Bordreuil, and G. Fras \\ Laboratoire de Mécanique et de Génie Civil LMGC- UMR5508, Univertsité Montpellier 2, Montpel- \\ lier, France
}

\begin{abstract}
Hot cracking is a critical defect frequently observed during welding of aluminium alloys. In order to better understand the interaction between cracking phenomenon, process parameters, mechanical factors and microstructures resulting from solidification after welding, an original hot-cracking test during welding is developed. According to in-situ observations and post mortem analyses, hot cracking mechanisms are investigated, taking into account the interaction between microstructural parameters, depending on the thermal cycles, and mechanical parameters, depending on geometry and clamping conditions of the samples and on the thermal field on the sample. Finally, a process map indicating the limit between cracking and non-cracking zones according to welding parameters is presented.
\end{abstract}

\section{Hot cracking in welds : state of art}

Aluminium alloys are highly sensitive to hot cracking phenomenon. It appears during solidification of the alloy, so it can be observed during welding, as well as during casting or other processes involving solidification. During welding, components are subjected to high thermal gradients around the melting zone due to localized heat input. Solidification area, located at the rear of the melting zone, corresponds to a "mushy zone" where liquid and solid phases coexist. When solidification speed is not too high, the mushy zone is ranged between two isotherm surfaces corresponding to liquidus and solidus temperatures. However, for high solidification speed, the temperature range of the mushy zone is moved due to undercooling [1].

Hot tearing phenomenon is generally associated to a lack of ductility of the mushy zone when liquid fraction becomes too low. The material sensitivity to hot tearing can then be characterized by the ductility into a "Brittle Temperature Range" (BTR) corresponding to the interval between the "coherency temperature", where the liquid does not easily circulate because of the low permeability of the solid skeleton, and the "coalescence temperature", where the solid opposes mechanical resistance (Figure 1) [2]. The solidification range width depends on the thermal gradient. The alloy studied (6061) has a wide range of fragility, the BTR is between $570^{\circ} \mathrm{C}$ and $600^{\circ} \mathrm{C}$. The heat load imposed by welding parameters, induced in this interval fragility fragile microstructure and mechanical loading overall facilitating crack initiation.

However, the hot tearing sensitivity is also correlated to the grain morphology in the mushy zone. It is generally admitted that columnar dendrite morphology, with dendrites growing in the thermal gradient direction, generally observed for low solidification speed and/or high thermal gradient [3], is more sensitive than equiaxe dendrite morphology. Hot tearing appears when the mushy zone is subjected to critical strain and stress fields. In welding, the mechanical loading is primarily produced by thermal strains due to temperature evolution around and in the mushy zone. High speed cooling after welding implies a solidification shrinkage (due to phase change) and thermal contraction of the solid skeleton (which depends on the expansion coefficient of the solid already formed). Added to

a e-mail: aurelie.niel@iut-nimes.fr

This is an Open Access article distributed under the terms of the Creative Commons Attribution-Noncommercial License 3.0, which permits unrestricted use, distribution, and reproduction in any noncommercial medium, provided the original work is properly cited. 


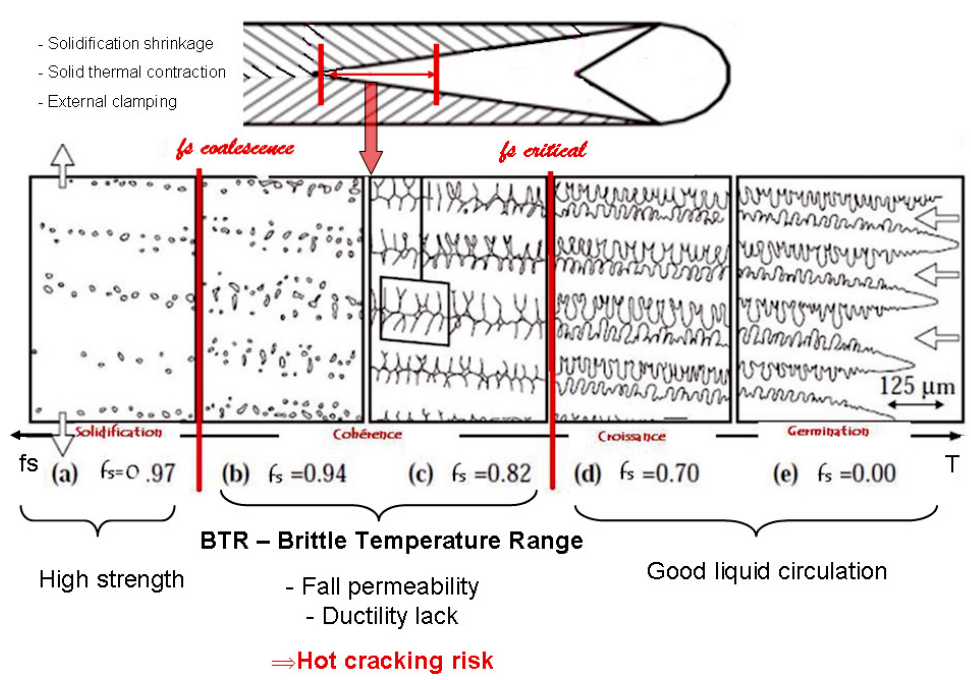

Fig. 1. Evolution of the microstructure of the mushy zone as a function of temperature.

these thermal strains, external clamping stresses can prevent the natural distortion. All these stresses can cause decohesion of liquid films, initiating the cracks.

Various hot tearing tests have been developed in order to study the alloys sensitivity [4]. They can be classified in two families: the self-clamping tests, where the mechanical loading of the mushy zone is produced by the thermal restrain of a bulk sample, and the external load test, like the Varestraint test, where a plastic strain is induced by a loading device during welding of the sample. These tests allow classifying alloys according to their sensitivity but do not develop quantitative criteria for each material.

The purpose of the present work is to study interaction between mechanical and metallurgical factors in order to better identify the parameters leading to hot tearing during welding. Originality of this study is to try distinguishing structural effects on a global scale in the face of microstructural effects on a local scale. An original test developed for hot tearing characterization in welding is first presented. Next, experimental results achieved in arc welding on a 6061 aluminium alloy are analyzed.

\section{The experimental system}

A simple original hot tearing test for thin plates has been developed in this study. The originality of this test is to apply a controlled tensile pre-stress along welding direction on a rectangular sample cut on thin aluminium plates of 0.8 to $3 \mathrm{~mm}$ thicknesses (figure 2). An automatic Gas Tungsten Arc Welding (GTAW) process has been chosen for these tests. With this process, electrical arc is created between a tungsten refractory electrode and the sample, in an inert gas, generally argon, to protect metal against oxidation.

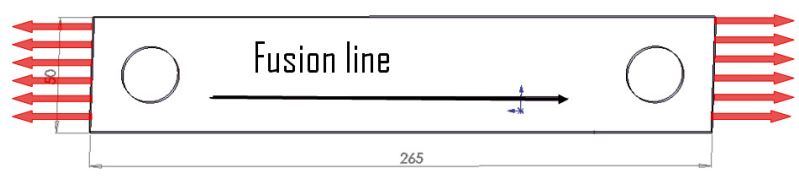

Fig. 2. Longitudinal tensile specimen with TIG fusion line. 
During welding, the specimen is clamped on both sides between two jaws. A fusion line is made with GTAW process on the aluminium sample along the longitudinal direction. A shift of the fusion line from the sample symmetry plane to one sample side (figure 2), or change of tensile pre-stress value, allow investigation of structural effects on hot tearing. The advantage of this test, compared to other hot tearing tests such as Varestraint test [4], is its simplicity which is interesting for an industrial use. In addition, the simple sample geometry and boundary conditions make easy 2D numerical simulation of the test.

Hot tearing test is placed on a mobile two axes $(\mathrm{X}, \mathrm{Y}$ ) table (figure 3). During a welding test, welding arc is in a fixed position and the sample is translated in the longitudinal direction at constant speed. In that way, observation of the weld pool with high speed camera is possible all along the test. With this test, microstructure control is possible by adjusting thermal cycle, depending on welding power and speed and samples size especially. Microstructural characteristics are observed using high speed camera recording and post mortem analysis. Mechanical factors are controlled by welding parameters adjustments, by the pre-stress applied thanks to the clamping system, and by the distance from the sample border to the fusion line. The present test then allows distinguishing between structural effects on a global scale and microstructural effects on a local scale.

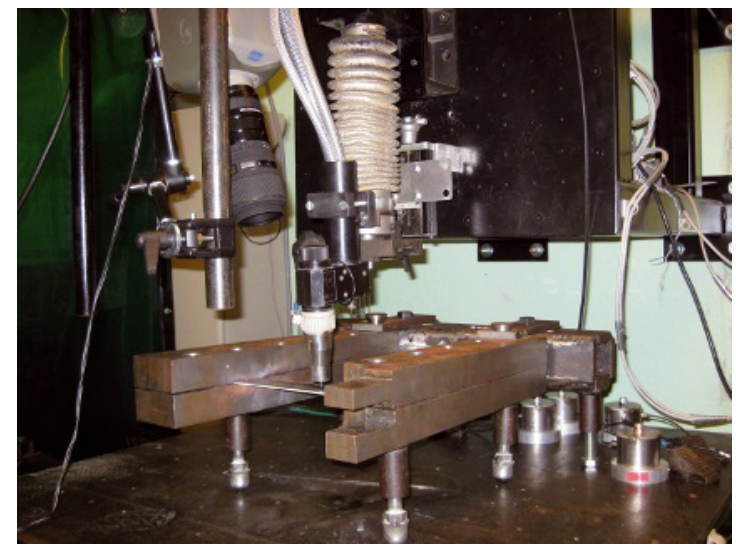

Fig. 3. Two axes table with hot tearing test.

A first test campaign was achieved in order to validate experimental device. 6061 alloy specimens, of dimensions $265 * 50 \mathrm{~mm}^{2}$ were water jet machined from $2.3 \mathrm{~mm}$ thick plates. During all these tests, a $200 \mathrm{MPa}$ preload is applied. High welding speeds in the range $5 \mathrm{~mm} / \mathrm{s}-20 \mathrm{~mm} / \mathrm{s}$, and $130 \mathrm{~A}-260 \mathrm{~A}$ current range were chosen for this first campaign. For each welding speed, current range are choosen to have a fully penetrated welding pool on the plate. A $3 \mathrm{~mm}$ arc length is imposed for all the welding tests, which corresponds to a welding voltage of about $10 \mathrm{~V}$.

\section{Experimental results}

\subsection{In situ study}

High speed camera recording of the mushy zone were made, in order to try to observe crack initiation. Mushy zone observation is complicated by the oxide formed at the weld pool surface. With an improved gas protection, the weld pool liquidus boundary appears (figure 4), and observation of the mushy zone is possible. We expect of these in-situ observations a better understanding of the hot tearing initiation concerning solid fractions and dendrite morphology.

Two areas with distinct granular structure can be generally observed on the in-situ recording, in the re-solidified zone: a columnar dendritic zone on the edges of the fusion zone, and an equiaxed dendritic 

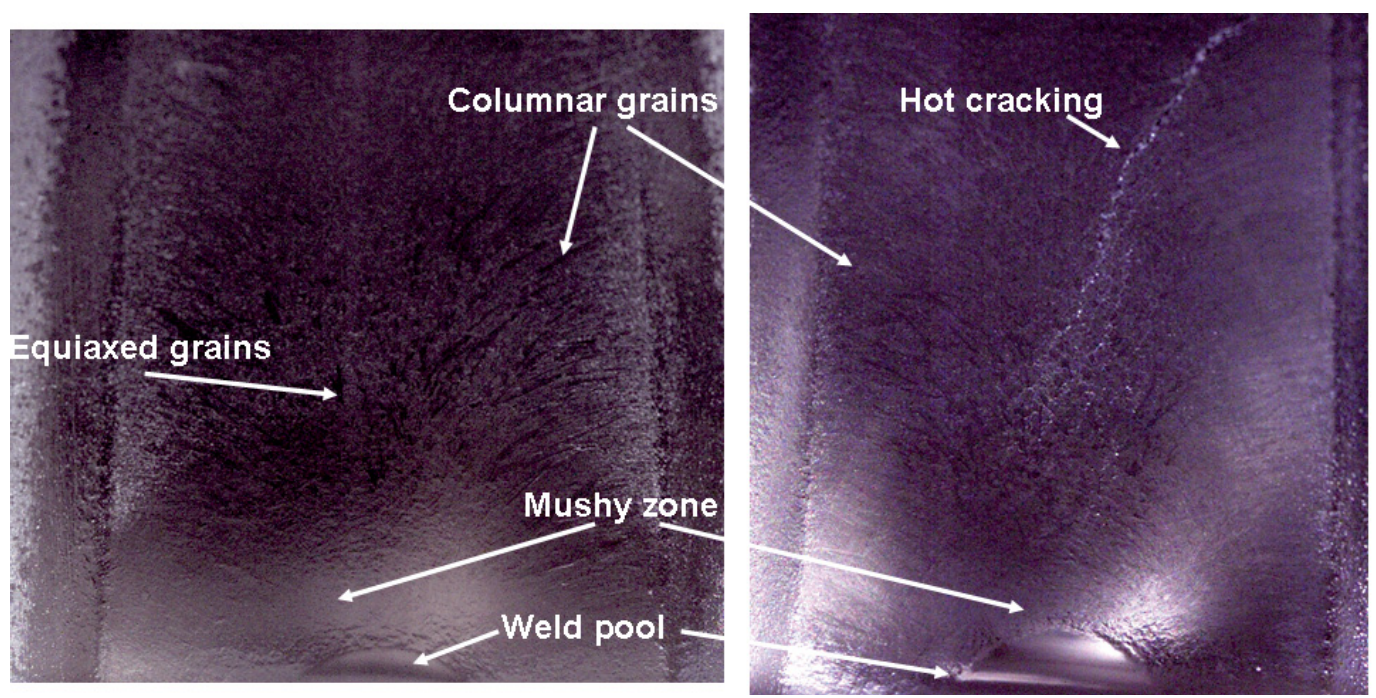

Fig. 4. Video recording image during welding showing the weld pool tail

zone in the center. However, at the lowest speed welding, the fusion zone is composed entirely of columnar dendritic grains.

Some theoretical considerations can explain these results. The formation of an equiaxe dendritic zone is promoted by the undercooling degree in the border between fusion zone and mushy zone. Undercooling is favoured by high solidification speed and low thermal gradient [3]. At high welding speed, solidification speed is high, but thermal gradient is too high on the edges of the fusion zone to create an equiaxe zone. So a columnar grain structure growing perpendicularly to the isothermal surfaces is formed. The thermal gradient is lower in the centre of the fusion zone, which explains the germination of equiaxe grains in this zone.

Moreover, when reducing the distance between fusion line and specimen border, we notice an asymmetry of the fusion zone structure. The columnar zone is then shorter in the sample border side. This can be explained by a lower thermal gradient on this side, because heat conduction in metal is reduced due to the sample border proximity.

Observation with high speed camera also shows that cracks initiate in the columnar zone, in a direction transverse to the welding direction. As a result, and depending on welding parameters, we observe a cracks stop in the equiaxe zone, or a bifurcation and a longitudinal cracks propagation, in the equiaxe grains zone.

\subsection{Post-mortem study of cracks morphology}

After welding, the formed cracks were first revealed by penetrant testing. The results highlight several failure modes, depending on process parameters. For high welding speed, some small transverse cracks are observed at the beginning of the welding line at the edges of the weld, which deviate rapidly to propagate in a large longitudinal crack (figure (5a)). Conversely, for low welding speed, the transverse cracks are more numerous, and do not deviate in a longitudinal direction.

Post mortem observations of the samples after welding at higher magnification allow to better analysing the hot tearing mechanism. Micrograph observations of cracks indicates a interdentritic fracture, typical of the hot tearing phenomenon (figure $5 \mathrm{~b}$ ). It has been confirmed with these observations that for most of the samples, the crack initiation occurs between the dendritic columnar grains. It is well known in literature that dendritic columnar grains are more sensitive to hot tearing than equiaxe dendrites [1]. The columnar grains are more sensitive to hot cracking, because the liquid flow up to the bottom of the columnar dendrites is much more difficult than between equiaxe grains. Thus the liquid can not come close the material lack, due to the solidification shrinkage, at the dendrite foot, and crack 

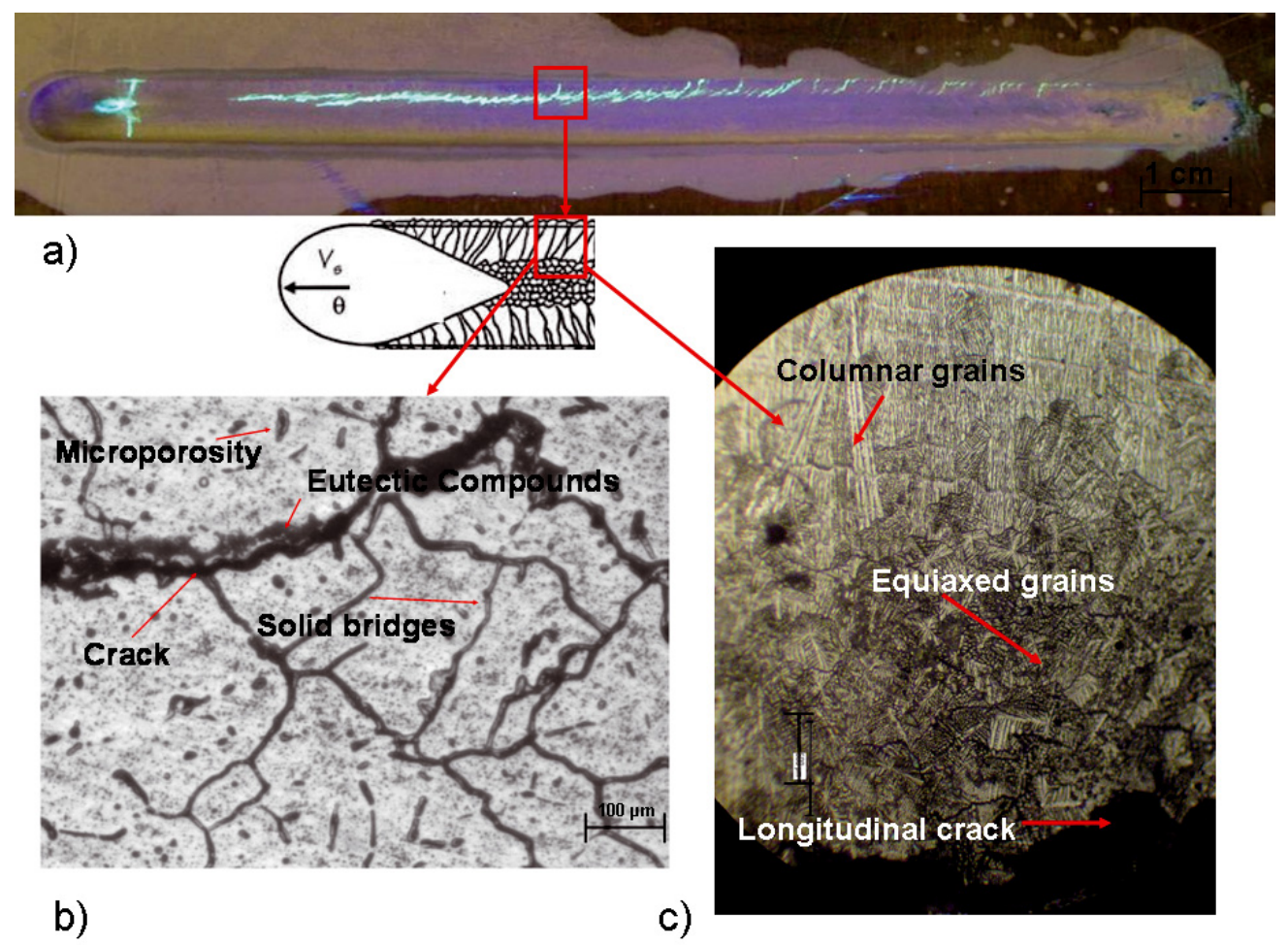

Fig. 5. a) Penetrant testing in a cracked specimen, b) Micrograph of a hot crack formed during welding of 6061 alloy (x 100) , c) columnar and equiaxe zones formed during welding of 6061 alloy.

initiation can occur. In addition, the longitudinal tensile preload applied favours transverse cracking between columnar grains.

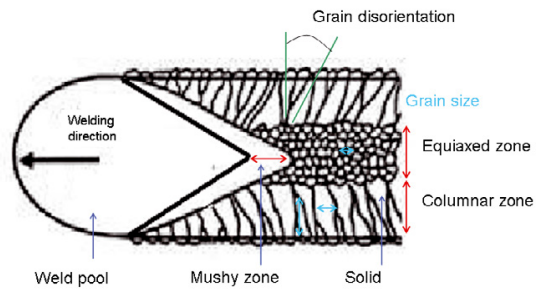

Fig. 6. Microstructural characteristics

Microstructural analyses also allow to characterize the morphology of the fusion zone, according to quantitative parameters, like the grain shape and size, there growth direction, the disorientation between dendrites, related to welding parameters, (figure 6), that can reflect a sensitivity to cracking. For instance, a central line emergence at the columnar dendritic grains junction increases hot cracking sensibility, according to Hunziker [1].

For our welding conditions, the central line is never observed, except for the lowest welding speed. At high welding speeds, the typical weld pool morphology previously described, composed of a central equiaxe grain area and peripherals columnar grain areas is observed. The average width of the columnar zones is about $1,5 \mathrm{~mm}$ on each side, and about $2 \mathrm{~mm}$ for the equiaxe zone. However the proportion of each one of both zones is a function of welding parameters. The crack width in the initiation area 
is about 30 microns, whereas it has an average value of 200 microns after longitudinal propagation in the central area. When the equiaxe zone width is small compared to the total width of the fusion zone, cracks tend to propagate more easily in a large longitudinal crack. Moreover, when the fusion line is shifted close to one edge, the cracks always initiate from that side. A thermal asymmetry is created in the weld bead. The disorientation between dendrites does not seem a crucial parameter on the crack initiation location, because the angle between two grains does not exceed $15^{\circ}$. The distance between the weld beginning and the first crack initiation is rather constant, between 2 and $4 \mathrm{~cm}$.

\subsection{Influence of process parameters}

The results of this first test campaign allow classifying welding parameters as cracking or not cracking conditions for a given tensile pre stress. Figure 7 shows the crack sensitivity evolution of 6061 alloy as a function of welding parameters.

It can be observed that large longitudinal cracks are only observed for high welding speed. However, low welding speed promotes columnar grains structure, which are more sensitive than equiaxe structure. This indicates that in our tests, mechanical effects, resulting from the evolution of stress and strain fields on the preloaded and clamped sample subjected to a local heating are more important than microstructural effects.

At high welding speed, cracking appears when the welding current reaches a critical value, depending on the welding speed. The understanding of the effect of the welding current on the hot tearing phenomenon is difficult, because it requires knowing the effect of this parameter on the strain and stress field in the sample. In order to better understand these effects, a numerical simulation of the welding test will be achieved, in parallel to experimental investigations.

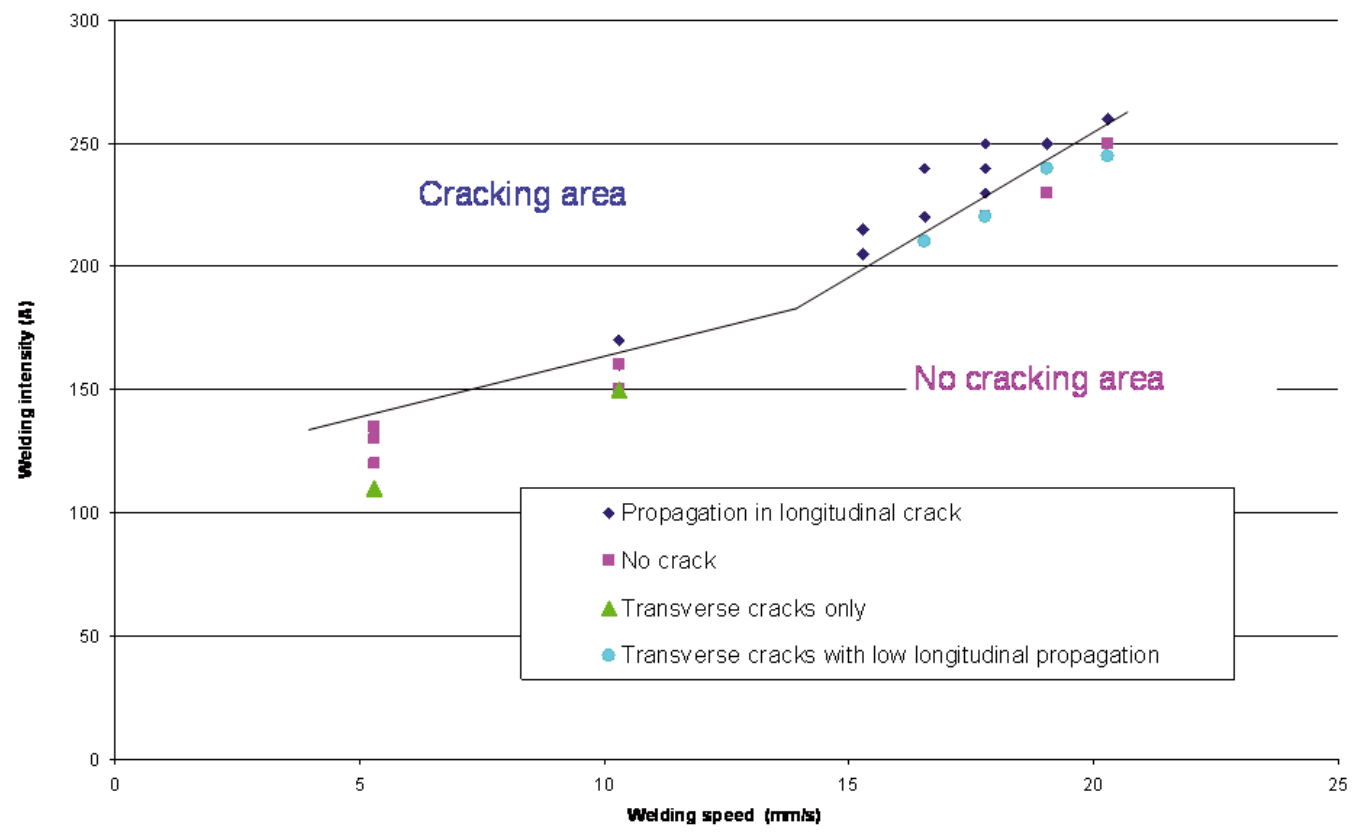

Fig. 7. Hot cracking map. 


\section{Conclusion}

It has been demonstrated in this study that solidification cracking is a many faceted problem, with many influencing parameters including relationship between mechanical aspect induced by process and microstructure. The test developed in this study is a simple test and can be used by industry. It allows the initiation of cracks du to welding parameters and applied pre-stress.

Observation using hight speed camera allows to better understand the mechanisms of crack initiation and of crack bifurcation at the grain scale. For our welding conditions, microstructure is always composed of a central equiaxe zone and a peripheral columnar zone where the crack initiation take place. The characteristic lengths of the microstructure measured can be introduced as influencing parameters of crack sensitivity.

Moreover, the process map representing the cracking zone according to welding parameters could be a useful tool to define welding conditions avoiding hot cracking. In addition, different crack propagation modes have been distinguished on this map, which allow a better understanding of the relations between welding parameters and hot cracking mechanisms.

This experimental study will be followed by the development of a criterion for crack initiation, based on the evolutions of the strain rate, permeability and microstructure of the mushy zone. This criterion will be applied as a post treatment of a finite element calculation of the welding hot-cracking test. According to these numerical results, some way of improvement of the process will be investigated, based on changes of the heat flux or of the boundary conditions applied to the sample during welding.

\section{References}

1. Hunziker, On formation of a centerline grain boundary during fusion welding. Acta mater. 48, 2000, 4191-4201.

2. Rappaz, Drezet, Gremaud, A new hot tearing criterion Metallurgical and materials transactions A 1999, 30A, 449, (1999).

3. Gaumann, Nucleation ahead of the advancing interface in directional solidification, Materials science and engineering, A226-228, (1997).

4. Cartaud, Essais de fissuration à chaud : principes et critères d'application, Soudage et techniques connexes, vol. 49, No 9-10, (1995). 